\title{
Is Profit Evil? Associations of Profit with Social Harm
}

\author{
Amit Bhattacharjee, Jason Dana, and Jonathan Baron \\ University of Pennsylvania
}

\section{PRELIMINARY DRAFT - PLEASE DO NOT QUOTE WITHOUT PERMISSION}

In opposition to foundational economic principles, four studies show that people view profit as fundamentally socially harmful. Studies 1 and 2 find a strong negative correlation between profit and perceived social value across both real firms and entire industries. This relationship holds for both perceived profit and actual profit information from public data. Study 3 confirms that this effect holds when profit motive is manipulated. Otherwise identically-described organizations are seen as providing less value and doing more harm when described as "for-profit" rather than nonprofit. Study 4 demonstrates that people hold a zero-sum conception of profit that neglects the disciplining effects of competition. People see harmful business practices as profitable, even after an intervention encouraging consideration of long-term consequences. This tendency is unrelated to self-reported political ideology. Even in one of the world's most market-oriented cultures, people doubt the ability of profit-seeking business to benefit society.

Key words: heuristics, economic psychology, profit, social welfare

\section{Introduction}

Human life expectancy increased from about 45 years to 77 years during the twentieth century, a rise at least partially attributable to the development of drugs such as antibiotics by the pharmaceutical industry (Kola and Landis 2004). Similarly, Henry Ford's innovations in manufacturing made automobiles affordable and ubiquitous, revolutionizing transportation and reshaping the national infrastructure (Levitt 1960). More recently, entrepreneurs and start-ups raced to connect the world by laying miles of fiber optic cable, ushering in the modern internet era (Friedman 2005).

Advances in human welfare such as these became possible because private firms assumed the staggering costs of research and development in hopes of making profit. While they differ in their views 
on the extent to which markets are effective, economists across the political spectrum agree that profits provide firms with incentives for creating value, and that prices are usually determined by supply and demand (Caplan 2007). Thus, while the effectiveness of different economic systems is disputable, economic first principles suggest that profit is not itself a bad thing. As the liberal economist Charles Schultze (1977) noted, "harnessing the 'base' motive of material self-interest to promote the common good is perhaps the most important social invention mankind has yet achieved." In market-oriented societies such as the United States, profit through commerce is the mechanism by which self-interest is used to create social value. Profits provide the incentive to innovate, move resources to more-valued industries, and produce more efficiently (Caplan 2007). Arguably, providing value to society is the only way to sustain profitability (Drucker 1954), and a growing body of empirical evidence associates value creation with superior firm profits (Economist 2000, Kirca et al. 2005). The scholarly consensus is that profits arise as part of a win-win situation in which the pie becomes larger, leading to larger slices for both consumers and producers (Caplan 2007, Drucker 1954, Levitt 1969).

\subsection{Anti-Profit Beliefs}

Conversely, the portrayal of profit-seeking as intrinsically sinful or harmful has been a common theme in art and literature from Biblical times to the modern day (Ribstein 2009). Economists have long noted that this association between profit and depravity is robust across cultures and historical contexts (Schumpeter 1954), but little work has directly examined perceptions of profit. Given the recent financial crisis and resulting public reaction, including the Occupy Wall Street movement, it is perhaps as important as ever to understand differences between scholarly and lay perceptions of business profit and its impact on society.

While prior research has examined the implications of the concept of money on social behavior (Dunn et al. 2008, Vohs et al. 2008), or on perceptions of price fairness in specific scenarios (Bolton et al. 2003, Campbell 2007, Kahneman et al. 1986), lay perceptions of business profit remain largely unstudied. In the spirit of recent research that examines lay beliefs concerning economic concepts and social welfare (Aaker et al. 2010, Norton and Ariely 2011), we propose and demonstrate that people hold anti-profit beliefs. Rather than viewing profit as the reward for providing the goods and services that people most desire, or innovations in the production process, the lay public views profit as arising from harmful practices, such as charging exorbitant prices, reducing quality, and exploiting labor. That is, people view profit as taken rather than created, just as people often erroneously view negotiations as having a winner and a loser even when they are win-win (Baron et al. 2006). By overlooking the possibility of growing the pie, anti-profit beliefs treat profit as necessarily leaving others with smaller slices. Unless people favor firms over consumers, they will thus see profit as social harm. Our studies show that this is the case even 
in one of the most market-oriented societies in human history, in which market norms are well integrated into cultural life (Fiske 1992).

\subsection{Market Norms vs. Moral Norms}

If the scholarly consensus is that profit reflects value to society, how could lay intuitions be so contrary? One possible reason is that people apply norms that govern behavior in the personal realm to the market realm. In the personal realm, excessive self-interest is often harmful because it inhibits socially beneficial cooperation. Moral norms typically curb self-interest and prescribe more attention to others, promoting greater social good. A firm's level of profit appears similar to excessive self-interest when taken statically, because more profit to the firm yields less surplus to the consumer at that point in time.

There are problems, however, with transplanting moral norms from the personal realm directly to the marketplace. Just as adhering to selfish market norms damages personal interactions (Heyman and Ariely 2004), applying moral norms to the market undermines its function (Clark and Mills 1979; Fiske 1992). The social benefits of profit are best understood through dynamic considerations of its incentive effects. Without the possibility of profit, firms would lack the motivation to make costly investments in valuable products and technologies, ultimately shrinking the societal pie. Further, profits attract entry into the marketplace, encouraging competition to provide these products and technologies more efficiently, to the benefit of society. Because people routinely fail to consider such secondary effects (McCaffery and Baron 2006), especially those displaced in time, the immediate negative aspect of profit is much more readily perceived than its benefits, which are less intuitive and more long-term. Indeed, it is only within the last 250 years that people have really begun to understand how self-interest can be harnessed for social good in this manner (Shermer 2008).

In the unrealistically ideal case of a perfectly functioning market, business profit would be equivalent to social value. Of course, markets do not always function perfectly. In cases of market failure, such as monopolies, profits arise from sources other than social value. These situations are the exception rather than the rule, however, and their prevalence may be overestimated by laypeople (Stiglitz 2002). Even scholars who have highlighted the shortcomings of the market (e.g., Kasser et al. 2007) agree that our profit-driven economic system has produced tremendous technological innovation and provides society with unprecedented value. We test whether the lay view more closely resembles the opposite extreme: a perfect market failure, in which profit is equivalent to social harm. This view implies that markets are persistently dysfunctional and perversely reward the most harmful actors, and that supply and demand do not usually determine prices. In other words, this worldview treats firms as "monopolists of varying altriusm" (Caplan 2007, p. 35) whose levels of profit reflect only the selfishness of their motives (Bolton et al. 2003, Campbell 2007). 


\subsection{Study Overview}

If our proposed account is correct, then we should observe a strong negative correlation between profit and perceived social value. Further, this association should be driven by intuitions reflecting a fixed pie (i.e., a zero-sum conception of profit). Indeed, Studies 1 and 2 demonstrate that the profit of both Fortune 500 firms and entire industries is strongly negatively correlated with perceived social value. This relationship holds whether profit is measured by respondents' perceptions or, in the case of individual firms, by actual net incomes from public data. Importantly, profits are seen as undeserved, coming at the expense of others, resulting from insufficient competition, and driven by differences in firm motives. Study 3 provides causal evidence for the role of profit in judging value: the otherwise identically described practices of hypothetical organizations are viewed as less socially valuable when the organizations are described as for-profit rather than non-profit. Study 4 examines our proposed mechanism at a more molecular level, showing that profit is seen as reflecting various harmful businesses practices as opposed to innovation and provision of value. These associations are unrelated to selfreported political ideology, and are robust to an intervention that encourages long-term thinking about the effects of competition.

\section{Study 1: More Profitable Firms Are Seen As Socially Harmful}

Our first study was intended to explore whether people hold anti-profit beliefs. Accordingly, we sought to assess perceptions of profit for actual firms with which our respondents were familiar. We expected that firms perceived to be more profitable would be seen as less valuable to society, and that profits would be seen as coming at others' expense.

\subsection{Method}

Eighty-five North American adults (34\% male, mean age 45) who signed up to do studies for pay through a web panel completed the study for $\$ 5$. Subjects rated their perceptions of 40 firms sampled from the Fortune 500 list of highest-grossing public corporations (Fortune 2010). We randomly sampled 8 firms from each quintile of the list, subject to the constraints that the firms were recognizable to non-experts and profitable in the past year. Each firm was presented with a short description (e.g., "Kraft Foods Inc. manufactures and markets snacks, confectionery, and quick meal products worldwide.”).

Subjects first indicated their familiarity with the firm on a 3-point scale $(1=$ Never heard of it, $3=$ Familiar). Next, they rated the firm on perceived profit ("How much profit do you think this business made on the average (of businesses in general) in the last year?"; $0=$ Zero or less, $5=$ A lot more than average). Subjects then indicated whether they believed that this profit was deserved or not ("Is this 
amount of profit deserved or not?"; 1 = Less than what is deserved, $3=$ More than what is deserved) and the perceived value of the firm to society ("What do you think about the value of this business to society, on the whole?"; 0 = It would be better if it did not exist, 3 = It is important and useful). Finally, subjects provided their beliefs about the sources of firm profits ("Do profits for [this business] (if any) come at the expense of others?" and "Do these profits (if any) result from lack of sufficient competition?"; yes/no) and the motives of those that run the firm ("What are the most important motives of those who run this business?"; 1 = To serve society or consumers, 3 = To make money, regardless of the effect on others). Order of presentation of firms was randomized within each subject.

\subsection{Results}

2.2.1. Aggregate Effects. We omitted responses to firms for which the subject expressed no familiarity ( $\mathrm{n}=319$, or $9 \%$, of 3400 total subject-firm responses were omitted). As expected, mean ratings for profit and social value were highly negatively correlated across firms $(r(38)=-.62, p<.0001$; see Figure 1). Substituting the $\log$ of actual profit for perceived profit yielded a similarly strong correlation $(r(38)=-.59, p<.0001)^{1}$. Given that ratings of perceived profit and social value have some measurement error, these results suggest that, indeed, profit is nearly a proxy for social harm. However, it is possible that these perceptions are not necessarily rooted in a zero-sum view of profit, or that they reflect particular notions of social value that differ from our interpretations. To assess this possibility, we examined the mean correlations between perceived profit and items reflecting our proposed mechanism. As expected, more profitable firms were rated as more undeserving of their profits $(r(38)=.75, p<$ $.0001)$, profiting more at the expense of others $(r(38)=.76, p<.0001)$, more lacking in competition $(r(38)=.55, p<.001))$, and more motivated to make money regardless of the effect on others $(r(38)=$ $.61, p<.0001$; see Table 1). These results are consistent with the idea that people adopt a zero-sum view of profit as taken rather than created.

2.2.2. Individual-level Analyses. The correlations above address mean ratings of firms or industries across individuals. To analyze individual-level anti-profit perceptions, we employed linear mixed-effects models with crossed random effects for subjects and firms (Baayen et al. 2008; this method is generally robust with missing data), using Markov chain Monte Carlo (MCMC) simulation to generate p-values. Higher ratings of profit predicted lower ratings of social value, even with random slopes for profit for each subject $(b=-.053, p=.0114)$. Again, these results held using actual log profits $(b=-.103$, $p<.0001)$. We also examined individual differences by calculating within-subject correlations between perceived profit and perceived social value. Overall, $40 \%(n=34$ of 85$)$ of subjects exhibited a significant

\footnotetext{
${ }^{1}$ Perceived profit was strongly correlated with the log of actual profit $(r(38)=.73, p<.0001)$, suggesting that subjects' judgments of relative firm profitability were quite accurate.
} 
negative correlation $(p<.05$, uncorrected), indicating anti-profit beliefs, while $11 \%(\mathrm{n}=9)$ showed a significant positive correlation. Of course the former number $(\mathrm{n}=34)$ is much more than would be expected by chance $(5 \%$, or $n=4.25)$, but the latter number $(n=9)$ is also significantly greater than chance $(p=.026$, one-sided exact binomial test). Thus, although most subjects held anti-profit beliefs, a few subjects held pro-profit beliefs.

Figure 1: Relation Between Perceived Profit and Perceived Social Value Across Firms

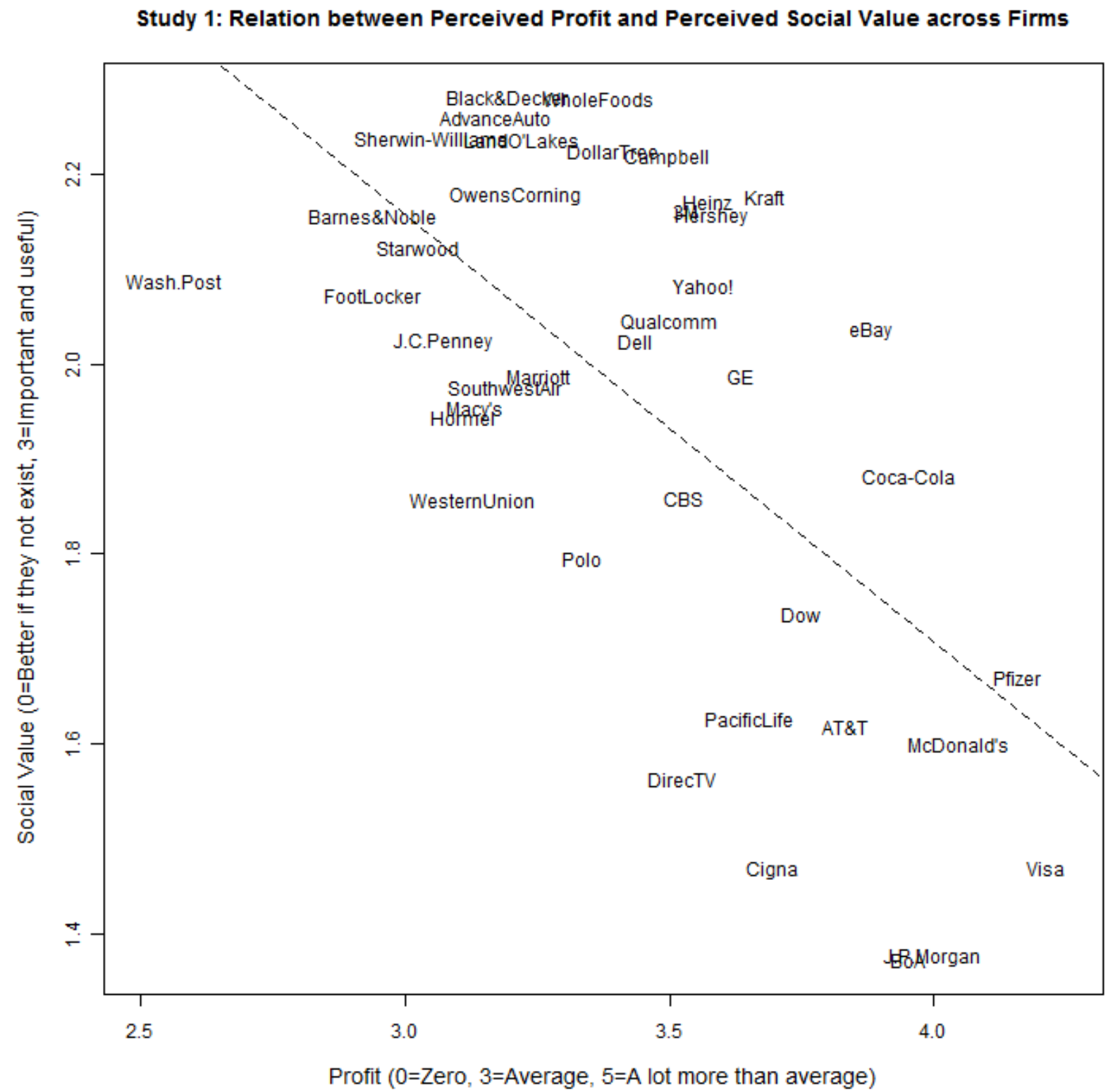

Note: Mean ratings of social value and perceived profit for individual firms in Study 1. The dashed line is the least squares linear fit. 


\subsection{Discussion}

As expected, our findings demonstrate a strong negative association between perceived profit and perceived social value. Results held for actual profit, suggesting that this pattern was not merely driven by inaccurate judgments of profit. More importantly, our mechanism measures indicate that subjects exhibited a zero-sum view of profit, ignoring the benefits of profit and the disciplining effects of competition. However, we found some heterogeneity: while many more subjects exhibited the expected negative association, over a tenth of our subjects actually held pro-profit beliefs. While we expect that this heterogeneity is driven by particular experiences with familiar, prominent firms, it is possible that antiprofit beliefs are less prevalent and less general than theorized. We conducted Study 2 to assess this possibility.

Table 1: Across-Item Correlations of Perceived Profit with Other Item-Mean Ratings

\begin{tabular}{lll} 
& Study 1 & Study 2 \\
\hline Social value & -.62 & -.67 \\
Not deserved & .75 & .93 \\
Others' expense & .76 & .75 \\
No competition & .55 & .50 \\
Profit motive & .61 & .76 \\
\hline
\end{tabular}

Note: All ps $<.001$.

\section{Study 2: More Profitable Industries Are Seen As Socially Harmful}

To look beyond particular firms with whom people may have had variable personal experiences, Study 2 tested types of firms (i.e., industries). If the overall negative association between perceived profit and perceived social value depends on certain firms, then we would expect this correlation to attenuate in judgments of entire industries. Conversely, if profit is used as a proxy for social harm, as we predict, then we should observe an even clearer negative correlation of perceived profit and percieved social value and less individual heterogeneity. Consistent with Study 1, we expected that even entire industries perceived to be more profitable would be seen as less valuable to society.

\subsection{Method}


Eighty-one North American adults (29\% male, mean age 44) who signed up through a web panel completed the study for $\$ 6$. Subjects rated 46 industries, each of which was listed with typical examples (e.g., "Investment banks (such as Morgan Stanley, Citigroup)"; "Metal producers (such as US Steel, Alcoa)").

All measures were identical to those used in Study 1, except with industries replacing individual firms. Subjects first indicated their familiarity with each industry. They then rated the industry on perceived profit. Next, they indicated whether they believed that this profit was deserved, and provided a judgment of the perceived value of the industry to society. Finally, subjects provided their beliefs about whether industry profits came at others' expense, whether they resulted from insufficient competition, and the primary motives of industry leaders. As before, order of presentation of industries was randomized within each subject.

\section{2. $\quad$ Results}

3.2.1. Aggregate Effects. We omitted responses to industries for which the participant expressed no familiarity ( $\mathrm{n}=117$, or $3 \%$, of 3726 total subject-industry responses were omitted). As in Study 1, mean profit and social value were highly negatively correlated $(r(44)=-.67, p<.0001$; see Figure 2$)$. This relation was directionally stronger than for firms, reinforcing the notion that profit and social value are seen as almost perfectly negatively correlated. To further assess whether our proposed mechanism holds in the case of industries, we examined the mean correlations between perceived profit and items reflecting our proposed mechanism. Again, as expected, more profitable industries were rated as more undeserving of their profits $(r(44)=.93, p<.0001)$, profiting more at the expense of others $(r(44)=.75, p<.0001)$, more lacking in competition $(r(44)=.50, p<.001)$ and reflecting greater profit motivation $(r(44)=.76, p$ $<.0001$; see Table 1). These results suggest that, even across industries, subjects view profits as coming at the expense of others and reflecting a failed market.

3.2.2. Individual-level Analyses. To look beyond aggregate relations and analyze individual-level anti-profit perceptions, we again used linear mixed-effects models with crossed random effects for subjects and firms (Baayen et al. 2008), using MCMC simulation to generate p-values. Higher ratings of profit predicted lower ratings of social value, even with random slopes for profit for each subject $(\mathrm{b}=$ $.187, p<.0001)$. We again calculated within-subject correlations between perceived profit and perceived social value. Overall, $73 \%(\mathrm{n}=59$ of 81$)$ of subjects exhibited a significant negative correlation $(p<.05$, uncorrected), indicating anti-profit beliefs, while only $2 \%(\mathrm{n}=2)$ showed a significant positive correlation. This time, the number of subjects with significant pro-profit beliefs $(n=2)$ is less than the chance expectation $(5 \%$, or $n=4.05)$. Thus, when judging entire industries, an overwhelming majority of subjects held anti-profit beliefs. 
Figure 2: Relation Between Perceived Profit and Perceived Social Value Across Industries

Study 2: Relation between Perceived Profit and Perceived Social Value across Industries

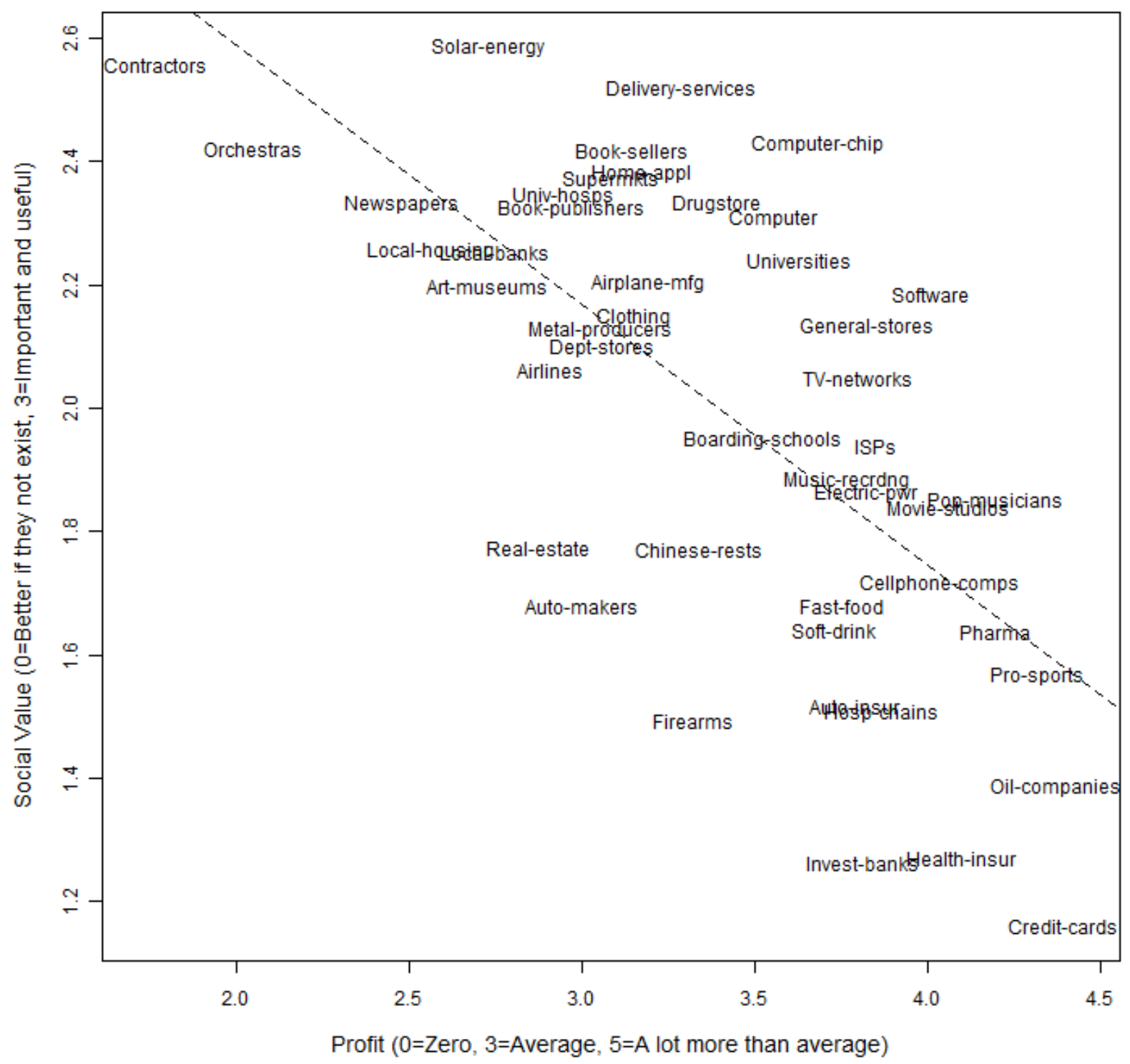

Note: Mean ratings of social value and perceived profit for entire industries in Study 2. The dashed line is the least squares linear fit.

\subsection{Discussion}

Our findings indicate a strong and robust negative association between perceived profit and perceived social value. As in Study 1, our results suggest that subjects hold a zero-sum view of profit and do not consider the disciplining effects of competition. Importantly, there was far less heterogeneity across 
individuals than we observed with firms. These findings suggest that variable individual experiences with particular firms may account for the greater heterogeneity in judgments in Study 1, and support the notion that people largely do associate profit with social harm.

\section{Study 3: Manipulated Profit Motive Increases Perceived Social Harm}

Studies 1 and 2 provide consistent correlational evidence of a strong negative relationship between perceptions of profit and social value. Since these studies dealt with real firms and industries, perceptions of the amount of profit were endogenous to subjects when they entered the study. For instance, one possibility is that subjects simply rated disliked companies as more profitable. While the actual profit results in Study 1 cast doubt on this explanation, Study 3 was intended to provide a cleaner test of our theorizing. In particular, we sought to establish the causal relationship of profit by exogenizing it and manipulating it experimentally. Because our evidence thus far suggests a key role for perceptions of differential profit motive, and in order to preserve accuracy, we manipulated the presence of a profit motive. We provided subjects with identical descriptions of hypothetical organizations and their practices, varying only whether they were described as for-profit or non-profit. Finally, in addition to asking about social value, we also included a measure of social harm and good to provide convergent evidence.

\subsection{Method}

One hundred adults were recruited through Amazon mTurk, a population known to be approximately $48 \%$ male with a mean age of 32 (Ross et al. 2010), to participate in exchange for financial payment, but 103 ended up completing the survey. Subjects read a series of hypothetical scenarios describing the practices of organizations across five different industries. The scenarios described: 1) an organization that requests volunteer donations of blood plasma and sells it to hospitals; 2) an organization that buys quality handmade jewelry and crafts from poor artisans in developing nations and sells them at high margins in retail outlets in developed nations; 3 ) an organization that buys the rights to promising new medical technologies from the inventors, then develops and sells the technologies to hospitals; 4) an organization that provides microloans to people in developing nations at high interest rates; and 5) an organization that sells Fair Trade coffee at higher prices so that small coffee farmers are paid more.

The key manipulation varied only whether the organization was described as a "for-profit corporation" or a "non-profit organization." In a between/within design, subjects viewed both versions of all five scenarios, randomly receiving either the entire for-profit block or non-profit block first. The order of presentation of the scenarios within blocks was randomized. After reading each scenario, subjects rated the organization on perceived social harm or good ("On the whole, how much social harm or good is accomplished by [the organization]?”; 1 = Much harm, 3 = No good or harm, 5 = Much good) and 
perceived value to society ("How much value for society does [the organization] create?"; 1 = None, $4=$ A great deal).

\subsection{Results}

We first analyzed within-subjects responses. Combining across scenarios, a repeated measures ANOVA revealed that subjects viewed the same organization as less socially good (i.e., more socially harmful) when it was described as for-profit $(M=3.32)$ versus non-profit $(M=3.46 ; F(1,101)=7.67, p=.007)$. Similarly, the same organization was rated as creating less value for society when it was described as forprofit $(M=2.59)$ versus non-profit $(M=2.70 ; F(1,101)=8.79, p=.004)$.

We replicated these effects in between-subjects analyses using only responses to the first presentation of each scenario. Again, across all scenarios, the organization was seen as less socially good ( $M=3.27$ vs. $3.53 ; F(1,101)=4.52, p=.036)$ and less valuable to society $(M=2.53$ vs. $2.76 ; F(1,101)=4.68, p=$ $.033)$ when it was described as a for-profit corporation. In both between- and within-subjects analyses, the direction of the effects was consistent in every scenario, underscoring the stability of this effect.

\subsection{Discussion}

As expected, profit-seeking per se was perceived to lead to less social value and greater social harm, even holding organizational practices constant. Notably, this effect was consistent and robust across a set of abstract scenarios with hypothetical organizations, a conservative test of our theorizing. These findings highlight the strength of this association and provide further support for our theoretical account.

\section{Study 4: Robust Beliefs About the Sources of Profit}

Our first three studies demonstrated that profit-seeking organizations are seen as more socially harmful, and greater profit is associated with greater social harm. Preliminary mechanism evidence from Studies 1 and 2 suggests that profits are seen as coming from a fixed pie and resulting from insufficient competition, and the association of profit with social harm holds even when profit-seeking is exogenized, as in Study 3. Building on these findings, Study 4 has three primary goals: 1) To assess beliefs about the sources of profit at a more molecular level by asking directly about various firm actions; 2) To distinguish between two possible explanations. People may not be considering that firms operate within markets, and are subject to competitive forces. Thus, when an intervention forces people to think about the long term implications of firm behaviors, their associations of profit with social harm could be attenuated. Conversely, people may simply neglect the incentive effects of profit, such that they believe harmful business practices are profitable even in the long term. In order to draw this distinction, we employed an 
intervention asking people about the long-term implications of various firm actions; 3) To test whether anti-profit beliefs can be explained by political ideology.

\section{1. $\quad$ Method}

Eighty-five North American adults (28\% male, with mean age 45) who signed up through a web panel completed the study for $\$ 5$. We selected 18 firms from the set of Fortune 500 firms used in Study 1 that were similar on perceived profit but varied in perceived social value. Each firm was presented with a short description (e.g., "Kraft Foods Inc. manufactures and markets snacks, confectionery, and quick meal products worldwide."). As in Studies $1-2$, subjects indicated their familiarity with each firm, their perceptions of its profitability in the last year, whether this profit was deserved, and its perceived value to society. Finally, subjects indicated whether profits came at others' expense, and their beliefs about the motives of those running each firm. Presentation order was randomized within each subject.

After completing these initial questions, subjects viewed descriptions of the same firms they had seen earlier in the same order, and answered the same questions about amount of profit, deservingness, value to society, whether profits came at the expense of others, and the motives of the firm's leaders. In order to further assess our proposed mechanism, we conducted an additional within-subjects manipulation. For a random half (either the first nine or second nine firms) of the firms, we included additional questions to examine subjects' beliefs and remind them of the long-term effects of competition. Specifically, we asked what each firm does to maintain its level of profits. On a series of three-point scales $(1=$ Not at all, $2=$ Somewhat, 3 = A great deal), subjects indicated their beliefs about potential sources of profit for each firm: overcharging ("It makes the profit it does because it charges more for the goods or services it sells.”), producing good products or services (“... because it produces a good product or service that people are willing to buy.”), low quality (“... because it produces lower quality goods or services so as to save money."), cost-reducing innovation (“...because it reduces costs through new ideas, while maintaining quality.”), underpaying labor (“...because it pays workers less.”), and safety shortcuts (“...because it takes safety shortcuts.”). Next, we directed subjects' attention towards long term implications of these firm behaviors to both assess their beliefs and act as a treatment. We asked about the effect of each of these behaviors on profits separately for each firm in the next five years, and subjects responded to each item on another three-point scale $(1=$ Reduce profit, $2=$ No effect, $3=$ Increase profit $)$.

Finally, we assessed political ideology. Three items asked specifically about the role of government in free enterprise on a series of five-point scales (e.g., "Free markets are better than government at providing what people need." $1=$ Never true, $5=$ Always true). A final item measured overall political orientation ("How would you classify your political views?" 1 = Very liberal, 3 = Moderate, 5 = Very conservative). 


\subsection{Results}

5.2.1. Aggregate Effects. We omitted responses to firms for which the subject expressed no familiarity ( $\mathrm{n}=45$, or $3 \%$, of 1530 total subject-firm responses were omitted). Though the number of firms was small, strong aggregate effects still emerged. As before, mean profit and social value were highly negatively correlated $(r(16)=-.67, p=.002)$. Mean correlations between perceived profit and our initial mechanism items also supported our earlier findings. Again, as expected, more profitable firms were rated as more undeserving of their profits $(r(16)=.86, p<.0001)$, profiting more at the expense of others $(r(16)=.75, p<.001)$, and exhibiting greater profit motivation $(r(16)=.74, p<.001)$. Given their consistency with our findings in Studies 1 and 2, these aggregate results seem reliable despite the lack of statistical power, and further indicate subjects' zero-sum view of profit. $^{2}$

5.2.2. Sources of Profit. To examine anti-profit beliefs at a more molecular level, we observed mean correlations of profit with subjects' judgments of the sources of firm profit, aggregating across firms (all items were asked separately for each specific firm). More profitable firms were judged to be charging significantly more than competitors $(r(16)=.54, p=.020$; see Table 2$)$, producing lower quality goods or services $(r(16)=.50, p=.032)$, and taking shortcuts with product safety $(r(16)=.56, p=.015)$. Producing high quality goods or services $(r(16)=-.12, p=.633)$, reducing costs through innovation $(r(16)=.21, p=.402)$, and underpaying labor $(r(16)=.16, p=.515)$ were not judged to be significantly associated with perceived firm profits. While there was very little statistical power for these aggregate correlations, we note simply that the latter correlations are smaller in magnitude. More importantly, we note the direction of the effects: greater harm was directionally associated with greater profit on five of our six measures.

5.2.3. Long-term Effects of Firm Actions. Next, we assessed beliefs about the effects of firm actions in the long term by examining the mean values of these items (all of which were asked separately for each firm). Aggregating across all ratings, charging more than competitors was thought to increase profits in the long term by most subjects $(M=2.45 ; 18 \%$ of responses $=$ reduce profit, $19 \%=$ no effect, $62 \%=$ increase profit). Similarly, underpaying labor was thought to increase long-term profits $(M=2.53$; $11 \%=$ reduce profit, $26 \%=$ no effect, $64 \%=$ increase profit). Interestingly, producing high quality goods and services $(M=2.81 ; 1 \%$ of responses $=$ reduce profit, $16 \%=$ no effect, $82 \%=$ increase profit $)$ and reducing costs through innovation $(M=2.80 ; 2 \%$ of responses $=$ reduce profit, $16 \%=$ no effect, $82 \%=$ increase profit) were both seen as increasing firm profit in the long term. Results were somewhat less conclusive for the perceived effects of producing low quality goods $(M=1.94 ; 42 \%$ of responses $=$

\footnotetext{
${ }^{2}$ As in Study 1, although most subjects $(54 \%, \mathrm{n}=46$ of 85$)$ showed significant $(p<.05$, uncorrected) negative correlations, a few subjects $(13 \%, \mathrm{n}=11)$ exhibited pro-profit beliefs, significantly greater than what would be expected by chance $(\mathrm{n}=4.25, p=.003$, one-sided binomial test).
} 
reduce profit, $22 \%=$ no effect, $36 \%=$ increase profit $)$ and taking safety shortcuts $(M=2.11 ; 28 \%$ of responses $=$ reduce profit, $34 \%=$ no effect, $38 \%=$ increase profit) on long-term profit, but it is notable that a majority of subjects believed that these practices would increase profit or have no effect in the long term. Overall, beliefs about the long-term effects of firm behaviors are mixed.

However, these beliefs were not always reflected in correlations of profit with subjects' judgments about long-term effects of behaviors by specific firms. Across firms, greater perceived firm profit was associated with the belief that overcharging is profitable in the long term $(r(16)=.60, p=.008$; see Table $2)$ and the belief that producing lower quality goods or services is profitable in the long term $(r(16)=.56$, $p=.016)$. Beliefs about producing high quality goods leading to long-term profit $(r(16)=-.31, p=.213)$, reducing costs through innovation leading to long-term profit $(r(16)=-.03, p=.892)$, underpaying labor leading to long-term profit $(r(16)=.24, p=.342)$, and safety shortcuts leading to long-term profit $(r(16)=$ $.32, p=.201$ ) were not judged to be significantly associated with perceived firm profits. Again, we note that statistical power was low for the aggregate analyses, but the directions of all six of these correlations are consistent with the idea that only harmful business practices are profitable.

5.2.4. Long-term Thinking Intervention. Next, we sought to assess the effects of our intervention. In asking subjects about the long-term implications of firm actions, we necessarily reminded them to consider the long term. To assess whether this treatment was effective in attenuating anti-profit beliefs, we employed linear mixed-effects models with crossed random effects for subjects and firms (Baayen et al. 2008), again using Markov chain Monte Carlo simulation to generate p-values. Higher ratings of profit significantly predicted lower ratings of social value $(b=-.103, p=.0001)$, while the intervention $(b=-$ $.062, p=.531)$ and the interaction of profit $\mathrm{x}$ intervention $(\mathrm{b}=.010, p=.726)$ had no effect. Thus, reminding subjects of the long-term implications of firm actions did not attenuate the negative relation between perceived profit and social value.

5.2.5. Political Ideology. Finally, we examined the effects of political ideology on anti-profit beliefs. Overall, $4 \%(n=3$ of 85$)$ of our sample classified its political beliefs as very liberal, $25 \%(n=21)$ was liberal, $35 \%(n=30)$ was moderate, $28 \%(n=24)$ was conservative, and $8 \%(n=7)$ identified as very conservative. This single-item measure of political ideology was poorly correlated with anti-profit beliefs (i.e., individual subjects' correlations of profit and social value; $r(78)=.11, p=.342$ ), beliefs about the sources of profit (combined in an index: $\alpha=.57 ; r(83)=-.07, p=.531$ ), and beliefs about the long-term effects of firm actions (combined in an index: $\alpha=.60 ; r(83)=.00, p=.997)$. An index combining all four ideology items $(\alpha=.71)$ was also poorly correlated with anti-profit beliefs $(r(78)=$ $.16, p=.169)$, beliefs about sources of profit $(r(83)=-.03, p=.809)$, and beliefs about long-term effects $(r(83)=-.06, p=.568)$. Results were identical when anti-profit beliefs, source-of-profit measures, and long-term-effect measures were regressed on all four separate ideology measures, as the overall R- 
squared was non-significant in each case. While self-described liberals held slightly stronger anti-profit beliefs, none of our analyses found significant results. Thus, our findings suggest that variation in antiprofit beliefs cannot be explained by political ideology alone.

Table 2: Across-Item Correlations of Perceived Profit with Perceived Sources of Profit

\begin{tabular}{lll} 
& Source of Profit & Long Term Effect \\
\hline Overcharging & $.54^{*}$ & $.60^{* *}$ \\
Producing Good Quality & -.12 & -.31 \\
Producing Low Quality & $.50^{*}$ & $.56^{*}$ \\
Reducing Cost Through Innovation & .21 & -.03 \\
Underpaying Labor & .16 & .24 \\
Taking Safety Shortcuts & $.56^{*}$ & .32 \\
\hline
\end{tabular}

Note: $* p<.05, * * p<.01$.

\subsection{Discussion}

Our findings lend further support to the notion that people associate profit with social harm. Building on Studies $1-3$, our results suggest that people view profit as more likely to arise from harmful practices (e.g., charging exorbitant prices, producing poor quality goods or services, cutting corners on safety) than benefic ial firm actions (e.g., producing high quality goods or services, reducing cost through innovation). While people's responses suggest that they believe that such beneficial actions will be profitable in the long term, these beliefs are not reflected in correlations with ratings of perceived profit of actual firms. For instance, perceived firm profitability is significantly associated with the belief that charging more and producing lower quality than the competition will increase profits in the long term. In fact, while our statistical power was limited, all six measures of long-term effects showed that profit is directionally associated with the belief that harmful behaviors are profitable in the long term. Moreover, a simple intervention reminding people of the long term implications of firm behaviors is not enough to attenuate anti-profit beliefs, and differences in political ideology cannot fully explain variation in anti-profit beliefs. In short, anti-profit beliefs appear robust.

\section{General Discussion}

People apparently have little faith in the power of markets to create and reward value for society. Across actual firms (Study 1, Study 4), entire industries (Study 2), and hypothetical organizations (Study 3), our 
subjects associated greater levels of profit, and profit-seeking itself, with social harm and less social value. Further, they saw greater profits as being undeserved, coming at others' expense, resulting from insufficient competition, and resulting from differences in the degree of profit motive. Though firms themselves were not seen as generally evil or devoid of value, profit was viewed as evil. Increasing firm profitability (or profit motive) greatly detracted from perceived social value. Indeed, people seem to exhibit an "ineradicable prejudice that every action intended to serve the profit interest must be anti-social by this fact alone" (Schumpeter 1954, p. 234). These results are quite in opposition to the view of profit espoused by economists and scholars that supply, demand, and competition will most reward profitseekers that provide what society wants. Thus, people's judgments about profit do not align with basic economic principles. Even in one of the most market-oriented societies in human history, people do not seem to believe in the possibility of the invisible hand.

Given that the exact relationship between profit and social value is unknown, are these beliefs actually erroneous? Perhaps scholars and laypeople simply differ in how they view profit, with neither view being incorrect. We note that while economists are not in perfect agreement about the extent to which profit reflects social value, the scientific arguments are over how much it reflects value, not whether it does. The scientific position of economists has emerged through systematic observation and rigorous analysis, while the views of laypeople arise through anecdote and intuition. To use an analogy, climate scientists disagree about how much, but not whether, human behavior impacts climate. While there is room for debate, naïve theories that deny human impact on climate fall far outside the scope of this scientific debate. Similarly, naïve theories that deny the value of profit fall far outside the scope of scholarly debate, and appear to be of no higher standing than naïve theories of climate change denial.

\subsection{Implications and Future Directions}

Our results could have several important implications that touch on multiple business disciplines. We contribute to the notion that consumer judgments of firms are driven by beliefs drawn from social contexts. For instance, firm judgments are subject to interpersonal stereotypes along dimensions of warmth and competence (Aaker et al. 2010), and inferences about firm motives may govern a range of such judgments (Campbell 2007). Such inferences may shed light on larger questions, such as what makes some firms (even those that are high-profit) more "bulletproof" in terms of consumer perceptions. For instance, in the retail sector, Wal-Mart is often vilified by the same consumers for whom the firm has created ample value (Furman 2005). Meanwhile, Target seems to enjoy greater consumer perceptions of social value, though some business commentators have specifically argued that its practices are less sustainable than those of Wal-Mart (Schwartz 2010). Understanding the social beliefs that shape firm judgments is critical for appropriate brand management and firm communications. 
While we employed broad measures of social value and social harm, another broad question concerns the dimensions of value that consumers can recognize and reward. In other words, what might explain the residuals of the regression lines in Figures 1 and 2? Interestingly, many of the types of businesses seen as relatively lacking in social value provide goods and services used on an everyday basis (e.g., credit cards, petroleum products, health and automobile insurance, cell phones). Because these goods and services are almost indispensable in today's world, the firms that provide them may arguably have the most social value. One possibility is that consumers have adapted to the social value of these goods and services because of their very prevalence. Looking above the regression line prompts a related question: what allows some types of businesses to be perceived as both highly profitable and socially valuable? Technology firms seem to cluster in this quadrant, and it is possible that the value of these goods is more tangible to people, or even that people recognize the incentive value of profit in fostering certain types of innovation. These are important and broad directions for future research to explore. Moreover, managers will benefit from knowing what dimensions and firm attributes to highlight in firm communications to minimize public perceptions of profit-driven social harm.

Deeper investigation of judgments of profit is another potential direction. While we focused on firms with positive profits in Studies 1 and 4, people may also see negative profits as indicative of social harm. Though our findings suggest that profit is seen as inherently bad, further such research may offer insight into judgments about the appropriate or normative level of profit for a given firm. Moreover, if profit and social value are seen as fundamentally in conflict, then socially responsible enterprise (Pallotta 2008) may be especially prone to being tainted by the contaminating influence of profit. Similarly, recent work demonstrates that firms in communally focused domains, such as religion and health care, may provoke negative consumer reactions when they employ tactics commonly used by profit-seeking firms (McGraw et al. 2012). Thus, a broader potential direction is to identify the boundary conditions around when market forces and external incentives are seen as especially corrupting. Such issues have implications for both firm and individual decisions.

From a policy perspective, if anti-profit beliefs are indeed biased and rooted in a misunderstanding of markets, they are an important target for economic education, as a misinformed public will choose systematically poor economic policies for itself (Caplan 2002, 2007). Greater economic knowledge may allow people to better act in accordance with their actual (i.e., enlightened) policy preferences (Althaus 2003, Caplan 2007). One potentially helpful perspective is to recognize that questions about social value and profit are difficult and complex ones for laypeople to answer. When faced with questions for which intuitive answers are difficult to generate, people may substitute a related question and answer that instead (Kahneman 2011). As such, in making a wide range of judgments about profit and profit-seeking institutions, our findings suggest that people may start by addressing simpler questions (e.g., substituting 
the simple question "Would I like if profits were more equally shared?" for the more difficult question "Is the system that allows some firms to profit more than others better than its alternatives?"). This account of heuristics - mental substitution of an easier question-may be an elegant way to capture how lay intuitions favoring dubious positions may nonetheless be held with a high degree of certainty (Caplan 2012).

Perhaps most importantly, lay beliefs about profit threaten the moral foundations of capitalism, which hold that to meet one's own needs, one must meet the needs of others by providing something of value. Correct or not, if people view profit as gained at the expense of society at large, then the market economy may impose psychological costs on the public (Kasser et al. 2007). A market society relies on the willing participation of its members, but individuals may be reluctant to participate in a system they view as morally bankrupt. Even if the market is an efficient means of allocating resources, as scholars stress, our profit-driven system could erode the very social fabric on which it relies for success. As the Occupy movement suggests, the public may reject a system in which profit is seen as taken rather than created.

\section{References}

Aaker, J., K.D. Vohs, C. Mogilner. 2010. Nonprofits are Seen as Warm and For-profits as Competent: Firm Stereotypes Matter. Journal of Consumer Research. 37 224-237.

Althaus, S. L. 2003. Collective Preferences in Democratic Politics: Opinion Surveyes and the Will of the People. Cambridge University Press, Cambridge, UK.

Baron, J., M.H. Bazerman, K. Shonk. 2006. Enlarging the Societal Pie Through Wise Legislation: A Psychological Perspective. Perspectives on Psychological Science. 1 123-132.

Baayen, R. H., D.J. Davidson, D.M. Bates. 2008. Mixed-effect modeling with crossed random effects for subjects and items. Journal of Memory and Language. 59 390-412.

Bolton, L.E., L. Warlop, J.W. Alba. 2003. Consumer Perceptions of Price (Un)Fairness. Journal of Consumer Research. 29 474-491.

Campbell, M.C. 2007. 'Says Who?!' How the Source of Price Information and Affect Influence Perceived Price (Un)Fairness. Journal of Marketing Research. 44 261-271.

Caplan, B. 2002. Systematically Biased Beliefs About Economics: Robust Evidence of Judgmental Anomalies from the Survey of Americans and Economists on the Economy. The Economic Journal. 112 433-458.

Caplan, B. 2007. The myth of the rational voter. Princeton University Press, Princeton, NJ.

Caplan, B. 2012. Eureka! Economic Illiteracy as Mental Substitution. Retrieved January 10, 2012, http://econlog.econlib.org/archives/2012/01/eureka_economic.html. 
Clark, M.S., J. Mills. 1979. Interpersonal Attraction in Exchange and Communal Relationships. Journal of Personality and Social Psychology. 37 12-24.

Doing Well by Doing Good. 2000. Economist. 355 65-67.

Dunn, E.W., L.B. Aknin, M.I. Norton. 2008. Spending Money on Others Promote Happiness. Science. 319 1687-1688.

Drucker, P.F. 1954. The practice of management. Harper \& Row, New York.

Fiske, A.P. 1992. The Four Elementary Forms of Sociality: Framework for a Unified Theory of Social Relations. Psychological Review. 99 689-723.

Friedman, T. 2005. The world is flat: A brief history of the twenty-first century. Farrar, Straus and Giroux, New York.

Furman, J. 2005. Wal-Mart: A Progressive Success Story. Working Paper. New York University, Wagner Graduate School of Public Service.

Heyman, J., D. Ariely. 2004. Effort for Payment: A Tale of Two Markets. Psychological Science. 15 787793.

Kahneman, D. 2011. Thinking, Fast and Slow. Farrar, Straus and Giroux, New York.

Kahneman, D., J.L. Knetsch, R.Thaler. 1986. Fairness as a Constraint on Profit Seeking: Entitlements in the Market. The American Economic Review. 76 728-741.

Kasser, T., S. Cohn, A.D. Kanner, R.M. Ryan. 2007. Some Costs of American Corporate Capitalism: A Psychological Exploration of Value and Goal Conflicts. Psychological Inquiry. 18 1-22.

Kirca, A.H., S. Jayachandran, W.O. Bearden. 2005. Market Orientation: A Meta-Analytic Review and Assessment of its Antecedents and Impact on Performance. Journal of Marketing. 69 24-41.

Kola, I., J. Landis. 2004. Can the Pharmaceutical Industry Replace Attrition rates? Nature Reviews Drug Discovery. 3 711-716.

Levitt, T. 1960. Marketing Myopia. Harvard Business Review. 38 45-56.

McCaffery, E.J., J. Baron. 2006. Isolation Effects and the Neglect of Indirect Effects of Fiscal Policies. Journal of Behavioral Decision Making. 19 1-14.

McGraw, A.P., J.A. Schwartz, P.E. Tetlock. 2012. From the Commercial to the Communal: Reframing Taboo Trade-offs in Religious and Pharmaceutical Marketing. Journal of Consumer Research. 39.

Norton, M.I., D. Ariely. 2011. Building a Better America - One Wealth Quintile at a Time. Perspectives on Psychological Science. 6 9-12.

Pallotta, D. 2008. Uncharitable: How Restraints on Nonprofits Undermine Their Potential. Tufts University Press, Lebanon, NH.

Ribstein, L.E. 2009. How Movies Created the Financial Crisis. Michigan State Law Review. 1-15. 
Ross, J., L. Irani, M.S. Silberman, A. Zaldivar, B. Tomlinson. 2010. Who Are the Crowdworkers? Shifting Demographics in Mechanical Turk. ACM Conference on Computer-Human Interaction. 2863-2872.

Schultze, C.L. 1977. The Public Use of Private Interest. The Brookings Institution, Washington, DC.

Schumpeter, J. 1954. History of Economic Analysis. Oxford University Press, New York.

Schwartz, A. 2010. Sustainability Faceoff: Walmart vs. Target. Fast Company. April 30.

Shermer, M. 2008. The Mind of the Market: How Biology and Psychology Shape Our Economic Lives. Times Books, New York.

Stiglitz, J.E. 2002. Globalization and its Discontents. Norton, New York.

Vohs, K.D., N.L. Mead, M.R. Goode. 2008. Merely Activating the Concept of Money Changes Personal and Interpersonal Behavior. Current directions in Psychological Science. 17 208-212. 